\title{
Self-Control as Predictor of Hope among Drug Addicts in Malaysian Rehabilitation Centers
}

Wan Mohammed Sallam Wan Sulaiman, Zainab Ismail, Wan Shahrazad Wan Sulaiman \& Razaleigh Muhamat@Kawangit

To Link this Article: http://dx.doi.org/10.6007/IJARBSS/v11-i3/8655 DOI:10.6007/IJARBSS/v11-i3/8655

Received: 11 January 2021, Revised: 10 February 2021, Accepted: 25 February 2021

Published Online: 13 March 2021

In-Text Citation: (Sulaiman et al., 2021)

To Cite this Article: Sulaiman, W. M. S. W., Ismail, Z., Sulaiman, W. S. W., \& Muhamat@Kawangit, R. (2021). Self-Control as Predictor of Hope among Drug Addicts in Malaysian Rehabilitation Centers. International Journal of Academic Research in Business and Social Sciences, 11(3), 688-699.

\section{Copyright: (c) 2021 The Author(s)}

Published by Human Resource Management Academic Research Society (www.hrmars.com)

This article is published under the Creative Commons Attribution (CC BY 4.0) license. Anyone may reproduce, distribute, translate and create derivative works of this article (for both commercial and non-commercial purposes), subject to full attribution to the original publication and authors. The full terms of this license may be seen

at: http://creativecommons.org/licences/by/4.0/legalcode

Vol. 11, No. 3, 2021, Pg. 688 - 699

Full Terms \& Conditions of access and use can be found at http://hrmars.com/index.php/pages/detail/publication-ethics 


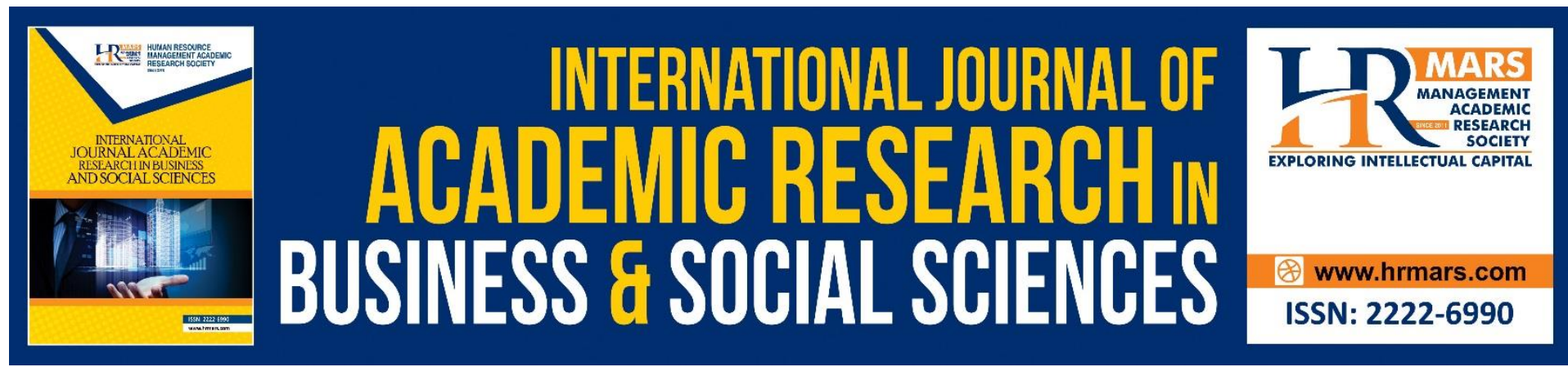

\title{
Self-Control as Predictor of Hope among Drug Addicts in Malaysian Rehabilitation Centers
}

\author{
Wan Mohammed Sallam Wan Sulaiman', Zainab Ismail'1, Wan \\ Shahrazad Wan Sulaiman² \& Razaleigh Muhamat@Kawangit' \\ ${ }^{1}$ Research Centre for Dakwah and Leadership, Faculty of Islamic Studies, Universiti \\ Kebangsaan Malaysia, ${ }^{2}$ Psychology Programme, Centre for Research in Psychology and \\ Human Well-being, Faculty of Social Sciences and Humanities, Universiti Kebangsaan \\ Malaysia \\ Email:shara@ukm.edu.my
}

\begin{abstract}
Self-control is an important psychological trait that drug addicts need to have to break free from addiction. However, many studies reported that self-control among drug addicts are still low, indicating problems in a drug-free life. This study therefore aimed to investigate the relationship between self-control and its dimensions with hope. This study also aimed to examine self-control dimensions as predictors of hope. This study employed a cross-sectional survey to collect data. A total of 244 samples were selected randomly from drug rehabilitation centers in Malaysia. Data were collected using a set of questionnaire consisting the SelfControl Scale (SCS) and Herth Hope Scale (HHS). The data were then analysed using Pearson correlation and multiple regression analysis. Results showed significant correlation between four dimensions of self-control (impulsivity, simple task, self-centeredness and temper) with hope. However, results found no significant correlations between risk-seeking and physical activities. In addition, impulsivity and temper were significant predictors towards hope. This study showed the significance of self-control to be incorporated in rehabilitation programmes of drug addiction to increase the effectiveness of treatment. This is important in the effort to reduce relapse and prevent individuals from getting involved in drug addiction.
\end{abstract}

Keywords: Self-control, Hope, Drug Addiction, Rehabilitation, Regression

\section{Introduction}

Drug addiction remains the top serious problem in Malaysia despite the efforts from the government to combat drug distribution and providing treatment and rehabilitation programmes. Statistics reported by the Malaysian National Anti Drug Agency (NADA, 2018) shows a decrease in new cases from 18,440 cases in 2017 to 17,474 cases in 2018, while for relapse cases it shows an increase from 7,482 cases in 2017 compared to 7,793 cases in 2018 (NADA, 2018). What is more worrying is the fact that this statistics in 2018 show the highest number of cases are among the youths (age 19 to 39 years old) with 18,417 cases compared to adults (more than 40 years old) with 6,300 cases and adolescents (age 13 to 18 years old) with 550 cases. This is a serious problem for the nation as this age group comprises of 
individuals who are supposed to be active and contributing people to the country's future development.

Many studies have been conducted to examine the contributing factors towards drug use. Most of these studies cluster the factors into protective and risk factors (NIDA, 2014). Among the protective factors are strong and positive family bonds, parental monitoring of children's activities and peers, clear rules of conduct that are consistently enforced within the family, involvement of parents in the lives of their children, success in school performance, strong bonds with institutions such as school and religious organizations, and adoption of conventional norms about drug use (NIDA, 2014). The risk factors on the other hand, are identified as chaotic home environments, particularly in which parents abuse substances or suffer from mental illnesses; ineffective parenting, especially with children with difficult temperaments or conduct disorders; lack of parent-child attachments and nurturing; inappropriately shy or aggressive behavior in the classroom; failure in school performance; poor social coping skills; affiliations with peers displaying deviant behaviors; and perceptions of approval of drug-using behaviors in family, work, school, peer, and community environments (Goldberg, 2013; Pokhrel et al., 2013; Kopak, 2014; NIDA, 2014; Roblyer et al., 2015).

Apart from that, psychological factors are deemed important factors to prevent drug addiction such as self-efficacy, coping strategy, self-awareness, self-determination and selfcontrol. According to Zavala and Kurtz (2017), drugs and substance abuse cases are related to low self-control. Evidently, many studies have found significant proofs in the relationship between low self-control and substance use. For example, Longshore et al. (2004) found that measures of drug use were higher among persons with low self-control, and that offenders with low self-control reported that a greater proportion of their peers were involved in substance use. Low self-control is also empirically related to problematic alcohol consumption, marijuana use, and other illegal drug use (Sun \& Longazel, 2008; Conner et al., 2008; Ford \& Blumenstein, 2012).

Self-control represents a personal decision arrived at through conscious deliberation for the purpose of integrating action which is designed to achieve certain desired outcomes or goals as determined by the individual himself. Another variable which is getting attention in psychological research is the role of positive psychology in identifying the potential of individuals to succeed in life. In particular, hope is a construct which has been recognized across disciplines as an important motivational state to overcome adversities in life such as the experience of life-threatening illnesses (Herth \& Cutcliffe, 2002). However, studies on the role of positive psychology in drug addiction in Malaysia are still few to gain understanding and contribute towards eradication drug issues. Therefore, this study aims to: (1) examine the relationship between self-control and hope, and (2) test the role of self-control dimensions as predictors of hope among drug addicts receiving rehabilitation programme.

\section{Literature Review}

The concept of hope is defined as an intrinsic element of life (Rines \& Montag, 1976), as an inner readiness for action (Weismann, 1973), as a perceived sense of the possible (Limandri \& Boyle, 1978), as a shared experience between giver and receiver (Marcel, 1962), and as an expectation of goal attainment (Stotland, 1969). Its growth was substantially centralized on 
two disciplines, nursing and psychology/psychotherapy. Dufault and Martocchio (1985) for example, distinguished between two forms of hope in cancer patients, generalized and particularized hope, and identified six dimensions; affective, cognitive, behavioral, affiliative, temporal, and contextual from their study of cancer patients.

The role of hope was explored among at-risks populations. Hope was found to be related to the risk for reoffending (Martin \& Stermac, 2010), positive rehabilitation constructs (Smedema et al., 2013), significant decrease of alcohol/substance craving (Shumway et al., 2013), and longer lengths of substance abstinence (Irving et al., 1998). Hope was reported to predict reported alcohol and drugs abstinence (Mathis, Ferrari, Groh, \& Jason, 2009), completion of alcoholism treatment (Strack, Carver, \& Blaney, 1987), substance abstinence and quality of life (Irving et al., 1998), and adolescents' avoidance of substance use (Carvajal et al., 1998).

Contrariwise, empirical contribution of self-control in contemporary literature is exhaustive. Self-control was found to be related to general deviant behaviours, family structure and neighbourhood disorder (Vera \& Moon, 2013), prisoners' nicotine dependence (Baniasadi et al., 2015), smoking initiation, cessation and relapse (Daly et al., 2016), fictitious drug use (Meldrum, Piquero \& Clark, 2013), intensification of criminal behaviour and the desistance from criminal activity (Zemel, Einat, \& Ronel, 2018), and substance misuse, suicidality, risky sex, criminal history, recidivism, and positive adjustment (Malouf et al., 2014). Self-control was also found to be associated with a manifestation of delinquent behavior (McNeeley, Meldrum \& Hoskin, 2018), drinking behavior (Foster, Young \& Bärnighausen, 2014), antisocial deviance, substance use problems, and measures of disinhibition (Venables et al., 2018), low marijuana use and low levels of depression over time (Pahl, Brook \& Lee, 2013), and decreased likelihood of committing crime (Skjærvø et al., 2017). Self-control was found to predict substance use and recidivism outcomes for parolees (Chintakrindi et al., 2015), craving in people with substance dependency (Basharpoor et al., 2014), problematic alcohol consumption and criminal behavior (Zavala \& Kurtz, 2017), heavy drinking and smoking among adolescents with low educational background (Davies et al., 2017), alcohol consumption and marijuana use (Koeppel, 2015), cocaine use among adolescents (Schaefer et al., 2015), gambling pathology (Cheung, 2016), and offending in late adulthood (Hirtenlehnera \& Baier, 2019).

Theoretically, self-control and hope share a certain logical parallel, as explained by Vohs and Schmeichel (2002), when they suggest that hopeful thinking is governed by self-regulation resources. This means that self-regulatory resources underlie successful acts of self-control and thus situationally predict a person's ability to obtain his or her goal. To explain further, hope is about goal realization, and that high hope leads to successful goal attainment (Snyder, 2000). Goal attainment involves a combination of processes starting from identifying the right goal, contriving means or routes towards it, to recognizing its completion. In this instance, a person needs to exercise self-control to accomplish this task, especially if the goal is related to self-betterment and/or behavioral improvement. A goal is usually set for something outside of the comfort zone as it tends to push one's ability to achieve something significant. If the goal is recovery from drug addiction behavior, then the exercise of self-control is crucial to buffer against the constant urge of craving that may instead jeopardize the whole operation. 
In addition, Vohs and Heatherton (2000) found that depletion of self-regulatory resources was related to the hope-related aspects of goal pursuit. Vohs et al. (2001) also found evidence on the relationship between hopeful thinking and self-regulatory resources in a subsequent self-control task. In another study, Neufeld and O'Rourke (2009) reported that impulsivity (one of the six dimensions of self-control) is similar to hopelessness, as both predict suiciderelated ideation and behavior among older adults at risk of self-harm. Studies have also suggested that counseling process necessitates corroborated motivation and sense of selfcontrol for goal attainment only second after its first priority, which is determination of goals (Guo \& Law, 2013; Snyder \& Harris, 1991; Snyder et al., 2006).

\section{Research Objectives \\ Research Design}

This research is a survey-based, exploratory descriptive analytical correlational crosssectional study. The location of this study is at designated Cure and Care Rehabilitation Centres (CCRC) running the ISRA program in Peninsular Malaysia. The selection of these locations are due to the fact that the ISRA program is still in its early commencement, and that there are currently only three ISRA-CCRC operating in Peninsular Malaysia (NADA, 2018).

This research uses a probability sampling technique. This research studies the clients of CCRC who are participating in the ISRA program in Peninsular Malaysia. As of 2017, the number of ISRA participants throughout the Peninsular Malaysia is 863 in three Remand Centres (NADA, 2018). A total of 244 samples were selected randomly from three drug rehabilitation centers under the control of the National Anti Drug Agency (NADA), Malaysia. The inclusion criteria for this data collection were clients who have undergone rehabilitation program for at least 3 months since their first admission, able to read and write on their own and had no prior diagnosis of physical or mental health problems.

\section{Research Instruments}

The researcher used a set of questionnaire involving the Grasmick et al. (1993) Self-Control Scale (SCS) and the Herth Hope Scale (HHS). Self-control Scale (SCS), consisting of a 24-item cognitive-based, four-point scale (Grasmick et al., 1993) based on the six dimensions of low self-control traits conceptualized in Gottfredson and Hirschi's General Theory of Crime (Gottfredson \& Hirschi, 1990). Six essential dimensions are hypothesized to constitute an invariant, multidimensional low self-control trait: impulsivity, simple tasks, risk seeking, physical activities, self-centeredness, and temper (Grasmick et al., 1993; Arneklev et al., 1999; Piquero \& Rosay, 1988). The Herth Hope Scale on the other hand consists of 30 items measuring three dimensions which are cognitive-temporal, affiliative-contextual and affective-behavioral.

\section{Results}

\section{Demographic Profile}

Out of 244 samples, all respondents were males with $32.80 \%$ of the samples were under 30 years, $43 \%$ between $31-40$ years of age, $20.5 \%$ between $41-50$ years, and $3.7 \%$ over age of 51. About $61.5 \%$ were single and $24.2 \%$ were married, while another $14.33 \%$ were widowed or divorced. Regarding respondents' previous occupation, about $4.5 \%$ were unemployed, $75.8 \%$ were self-employed, $3.7 \%$ were government employed while $16 \%$ were employed in the private sector. Majority of the samples with $67.21 \%$ had high school education, $20.9 \%$ had 
primary school education and $11.89 \%$ had diploma and skills certificates. Majority of the respondents (89.9\%) had previous religious education while $10.1 \%$ had no previous religious education. The data also showed that $69.3 \%$ of respondents had been in the rehabilitation centre once, $22.5 \%$ had been in the centre twice, $6.6 \%$ had been in the centre three times and $1.6 \%$ had undergone rehabilitation program more than 3 times. This showed that a total of $30.7 \%$ of the respondents were recidivists, meaning that they had repeatedly undergone drug rehabilitation programs but failed to leave their addiction. Table 1 presents the demographic data on samples.

Table 1: Demographic Data

\begin{tabular}{llll}
\hline Demographic & & (N:244) & Percent (\%) \\
\hline Age & $21-30$ years & 80 & 32.80 \\
& $31-40$ years & 105 & 43.00 \\
& $41-50$ years & 50 & 20.50 \\
& $51-60$ years & 9 & 3.70 \\
\hline Status & Single & 150 & 61.50 \\
& Married & 59 & 24.20 \\
& Widowed/Divorced & 35 & 14.30 \\
\hline Previous & Unemployed & 11 & 4.50 \\
Occupation & Self-employed & 185 & 75.80 \\
& Government employed & 9 & 3.70 \\
& Private sector & 39 & 16.00 \\
\hline Education & Primary school & 51 & 20.90 \\
level & High school & 164 & 67.21 \\
& Certificate/Diploma & 29 & 11.89 \\
\hline Previous & Yes & 222 & 89.90 \\
religious & No & 25 & 10.10 \\
education & & 169 & \\
\hline Frequency of & 1 & 55 & 69.30 \\
times in & 2 & 19 & 22.50 \\
Rehab & 3 & 4 & 6.60 \\
Centre & More than 3 times & & 1.60 \\
\hline
\end{tabular}

\section{Correlation between Self-Control and Hope}

Table 2 presents the results of correlation between dimensions of self-control and hope. The findings showed that there were significant correlations between impulsivity $(r=.362, p<$ $.0001)$, simple tasks $(r=.208, p<.0001)$, self-centeredness $(r=.219, p<.001)$ and temper $(r$ $=.257, \mathrm{p}<.0001$ ) with hope. However, results found no significant correlations between risk seeking $(r=.096, p>.05)$ and physical activities $(r=-.090, p>.05)$ with hope. 
Table 2 Correlations between dimensions of self-control and hope

\begin{tabular}{ll}
\hline Dimension & Hope \\
\hline Impulsivity & $.362^{* *}$ \\
Simple tasks & $.208^{* *}$ \\
Risk seeking & .096 \\
Physical activities & -.090 \\
Self-centeredness & $.219^{*}$ \\
Temper & $.257^{* *}$ \\
\hline \multicolumn{2}{c}{$* * \mathrm{p}<.0001, * \mathrm{p}<.001$}
\end{tabular}

\section{Self-control as Predictor of Hope}

The second objective of this study examines the roles of self-control dimensions as predictors towards hope. Multiple regression analysis was used to analyze the significant contribution of impulsivity, simple tasks, self-centeredness and temper towards hope. The regression model showed that the four dimensions of self-control significantly predicted hope with $17.6 \%$ variance, $R^{2}=.176, F(4,239)=12.79, p<0.0001$. Impulsivity was a significant predictor towards hope with Beta $=.29, \mathrm{t}=4.68, \mathrm{p}<.0001$. Temper was also a significant predictor of hope with Beta $=.14, t=2.12, p<.05$. However, simple task was not a predictor of hope with Beta $=.09, t=1.36, p>.05$. Self-centeredness also did not predict hope with Beta $=.08, t=$ $1.24, p>.05$. The results are shown in Table 3.

Table 3: Results of multiple regression analysis between self-control dimensions and hope

\begin{tabular}{lcccrc}
\hline \multicolumn{7}{c}{ Unstandardized } & Standardized & & \\
\hline & B & $\begin{array}{c}\text { Std. } \\
\text { Error }\end{array}$ & Beta & $\mathrm{t}$ & $\mathrm{p}$ \\
\hline Constant & 0.910 & .177 & & 5.153 & 0.000 \\
Impulsivity & 0.243 & .052 & 0.291 & $4.677^{* *}$ & 0.000 \\
Simple tasks & 0.063 & .046 & 0.086 & 1.362 & 0.174 \\
Self-centeredness & 0.051 & .041 & 0.079 & 1.238 & 0.217 \\
Temper & 0.095 & .045 & 0.138 & $2.116^{*}$ & .035 \\
\hline
\end{tabular}

\section{Discussion}

Findings of this study showed that impulsivity was a significant predictor of hope. This means the lower the impulsive trait, the higher the hope among respondents. Self-control can be seen to reflect self-discipline and conversely it indicates resistance to impulsive behaviours (Ferrari et al., 2012). Individuals who have high resistance to impulsive behaviours are more self-disciplined and consequently have more control in resisting the desire to continue taking drugs. Hence, this can provide hope for them to change their addictive behaviour and motivate them to overcome adversities in life (Herth \& Cutcliffe, 2002).

Results also showed that low temper was a significant predictor of hope. This means the lower the hot temper trait, the higher the hope among respondents. Self-control also indicates the ability of individuals to control their emotions and temper which is an important aspect in increasing hope to make changes in addictive behaviour. This is consistent with the concept of hope by Snyder (2000) who said that by having control of emotions and temper, individuals can then have the capabilities and motivation to achieve desired goals in life. 
Finally, the dimensions of self-centeredness and simple tasks were not significant predictors of hope. Individuals with high self-centeredness trait may find it difficult to obtain a drug-free life as many studies on drug addiction have found that one factor contributing to recovery is social support (Ellis et al., 2004; Lemos et al., 2012; Martin-Storey et al., 2011; Polcin \& Korcha, 2017). Self-centered individuals may ignore help and support from others and this can make addiction recovery more difficult to attain.

As hope is about goal realization and high hope leads to successful goal attainment, therefore individuals who only have abilities to focus on simple tasks would not be able to achieve difficult goals in life, especially the ability to maintain a drug free life and resist the desire to continue taking drugs. Goal attainment also involves a combination of processes starting from identifying the right goal, contriving means or routes towards it, to recognizing its completion (Snyder, 2000). This is consistent with the Transtheoretical Model of stages of change by Prochaska and DiClemente (1983) who described the maintenance stage as the most difficult stage as individuals need to sustain their behavior change for at least six months or more. People in this stage work to prevent relapse and if they cannot focus on this complex task, it is difficult for them to have hope in changing their behaviour.

\section{Conclusion}

This study aimed to examine the role of self-control and its' dimensions as predictors of hope among Drug Addicts in Malaysian Rehabilitation Centers. This study has shown that low scores in impulsivity and temper significantly predicted hope. The findings of this study give implications on the importance of incorporating self-control in drug rehabilitation and treatment programmes. Although the treatment and rehabilitation programmes for drug addicts are provided through institutional-and community based programmes, these programmes focus on various types of individuals. There is a need for specific psychological components in ensuring the effectiveness of recovery process.

The findings of this research have significant contributions in understanding drug recovery process. Theoretical contribution of this study supports Self-Control theory which states that individuals need to have low impulsivity, temper, self-centeredness and simple task in order to have high self-control. It also highlights the importance to consider constructs of positive psychology to empower individual potential. Contextual contribution of this research provides recommendations to improve treatment and rehabilitation programmes for drug addicts to increase its' effectiveness, and consequently contribute in reducing the statistics of drug addiction and relapse in Malaysia.

\section{Acknowledgements}

The researchers would like to express gratitude to the National Anti Drug Agency (NADA) Malaysia for approving this research and giving permission to distribute the questionnaires to participants at drug rehabilitation centres. The researchers also express gratitude to research project SK-2019-026 for funding part of the study.

\section{References}

Arneklev, B., Grasmick, H. G., \& Bursik, R. (1999). Evaluating the dimensionality and invariance of 'Low Self-Control'. Journal of Quantitative Criminology, 15, 307-331. 
Baniasadi, T., Javanmard, Z., Zivari-Rahman, M., Shokouhi-Moqhaddam, S., \& Adhami, M. (2015). Investigating the relationship between personality traits and self-control and nicotine dependence symptoms in male prisoners in Kerman, Iran. Addict Health, 7(12), 82-86.

Basharpoor, Sajjad, Khosravinia, Diba, Atadokht, Akbar, Daneshvar, Somayeh, Narimani, Mahammad, \& Massah, Omid. (2014). The role of self-compassion, cognitive selfcontrol, and illness perception in predicting craving in people with substance dependency. Journal of Practice in Clinical Psychology, 2(3), 155-164.

Carvajal, S. C., Clair, S. D., Nash, S. G., \& Evans, R. I. (1998). Relating optimism, hope, and selfesteem to social influences in deterring substance use in adolescents. Journal of Social and Clinical Psychology, 17(4), 443-465.

Cheung, N. W. (2016). Social strain, self-control, and juvenile gambling pathology: Evidence from Chinese adolescents. Youth \& Society, 48(1), 77-100.

Chintakrindi, S., Porter, J. R., Mellow, J., \& Sung, Hung-En. (2015). Empirical test of low selfcontrol theory using post-treatment substance use and recidivism outcomes of parolees participating in an experimental intervention. Criminology, Criminal Justice, Law \& Society, 16(2), 14-41.

Conner, B. T., Stein, J. A., \& Longshore, D. (2008). Examining self-control as a multidimensional predictor of crime and drug use in adolescents with criminal histories. The Journal of Behavioral Health Services \& Research, 36(2), 137-149.

Daly, M., Egan, M., Quigley, J., Delaney, L., \& Baumeister, R. F. (2016). Childhood self-control predicts smoking throughout life: evidence from 21,000 cohort study participants. Health Psychology, 35(11), 1254-1263.

Davies, L. E. M., Kuipers, M. A. G., Junger, M., \& Kunst, A. E. (2017). The role of self-control and cognitive functioning in educational inequalities in adolescent smoking and binge drinking. BMC Public Health, 17(1), 714-723.

Dufault, K., \& Martocchio, B. (1985). Hope: Its spheres and dimensions. Nursing Clinics of North America, 20(2), 379-391.

Ellis, B., Bernichon, T., Ping Yu, \& Roberts, T. (2004). Effect of social support on substance abuse relapse in a residential treatment setting for women. Evaluation \& Program Planning, 27(2), 213-221.

Ferrari, M., Harrison, B., \& Lewis, D. (2012). The risk factors for impulsivity-related falls among hospitalized older adults. Rehabilitation Nursing: The Official Journal of the Association of Rehabilitation Nurses, 37(3), 145-150.

Ford, J. A., \& Blumenstein, L. (2012). Self-control and substance use among college students. Journal of Drug Issues, 43(1), 56-68.

Foster, D. W., Young, C. M., \& Bärnighausen, T. W. (2014). Self-control as a moderator of the relationship between drinking identity and alcohol use. Substance Use \& Misuse, 49(10), 1340-1348.

Goldberg, C. (2013). Hispanic teen drug use significantly higher than other ethnic groups, substance abuse becoming normalized behavior among Latino youth. (2013). Retrieved from: $\quad$ http://www.drugfree.org/newsroom/new-survey-hispanic-teen-drug-usesignificantly-higher-than-other-ethnic-groups-substance-abuse-becoming-normalizedbehavior-among-latino-youth/

Gottfredson, M. R., \& Hirschi, T. (1990). A general theory of crime. Stanford, CA: Stanford University Press. 
Grasmick, H. G., Tittle, C. R., Bursik, R., \& Arneklev, B. (1993). Testing the core empirical implications of Gottfredson and Hirschi's General Theory of Crime. Journal of Research in Crime and Delinquency, 30, 5-29.

Guo, G. J., \& Law, F. M. (2013). The effectiveness of hope-based counseling in promoting a sense of hope, cognitive and behavior change, and self-esteem for female drug offenders in recovery. The Archive of Guidance \& Counseling, 35(1), 31-56.

Herth, K., \& Cutcliffe, J. R. (2002). The concept of hope in nursing: Research, education, policy and practice. British Journal of Nursing, 11(21), 1404-1411.

Hirtenlehnera, H., \& Baier, D. (2019). Self-control and offending in late adulthood: Investigating self-control's interaction with opportunities and criminal associations in advanced age. Journal of Criminal Justice, 60(C), 117-129.

Irving, L. M., Seidner, A., Burling, T., Pagliarini, R., \& Robbins-Sisco, D. (1998). Hope and recovery from substance dependence in homeless veterans. Journal of Social and Clinical Psychology, 17(4), 389-406.

Koeppel, M. (2015). How general is the General Theory of Crime? Using self-control to predict substance use between sexual orientation groups. Journal of Drug Issues, 45(1), 8094.

Kopak, A. M. (2014). Protective factors against substance use among multiethnic gangaffiliated youth. Journal of Ethnicity in Criminal Justice, 12(3), 194-217.

Lemos, V. A., Antunes, H. K., Baptista, M. N., Tufik, S., Mello, M. T., \& Formigoni, M. L. (2012). Low family support perception: A 'social marker' of substance dependence? Rev Bras Psiquiatr, 34(1), 52-59.

Limandri, B. J., \& Boyle, D. W. (1978). Instilling hope. American Journal of Nursing, 78(1), 7880.

Longshore, D., Chang, E., Hsieh, S., \& Messina, N. (2004). Self-control and social bonds: A combined control perspective on deviance. Crime \& Delinquency, 50(4), 542-564.

Malouf, E. T., Schaefer, K. E., Witt, E. A., Moore, K. E., Stuewig, J., \& Tangney, J. P. (2014). The Brief Self-Control Scale predicts jail inmates' recidivism, substance dependence, and post-release adjustment. Personality and Social Psychology Bulletin, 40(3), 334-347.

Marcel, G. (1962). Homo Viator: Introduction to a Metaphysic of Hope (Crawford, E., trans.). New York: Harper Torchbooks.

Martin, K., \& Stermac, L. (2010). Measuring hope: Is hope related to criminal behaviour in offenders? International Journal of Offender Therapy and Comparative Criminology, 54(5), 693-705.

Martin-Storey, A., Serbin, L. A., Stack, D. M., Ledingham, J. E., \& Schwartzman, A. E. (2011) Self and peer perceptions of childhood aggression, social withdrawal and likeability predict adult substance abuse and dependence in men and women: A 30-year prospective longitudinal study. Addict Behav, 36(12), 1267-1274.

Mathis, G. M., Ferrari, J. R., Groh, D. R., \& Jason, L. A. (2009). Hope and substance abuse recovery: The impact of agency and pathways within an abstinent communal-living setting. Journal of Group in Addiction \& Recovery, 4(1/2), 42-50.

McNeeley, S., Meldrum, R. C., \& Hoskin, A. W. (2018). Low self-control and the adoption of street code values among young adults. Journal of Criminal Justice, 56, 118-126.

Meldrum, R. C., Piquero, A. R., \& Clark, J. (2013). Does low self-control predict fictitious drug use and untruthfulness? Deviant Behavior, 34(3), 242-254. 
NADA. (2018). National Anti-Drugs Agency Drug Information, Ministry of Home Affairs. Retrieved from www.adk.gov.my/orang-awam/maklumat-dadah/

Neufeld, E., \& O'Rourke, N. (2009). Impulsivity and hopelessness as predictors of suiciderelated ideation among older adults. The Canadian Journal of Psychiatry, 54(10), 684692.

NIDA. (2014). Principles of substance abuse prevention for early childhood. National Institute on Drug Abuse (NIDA). Retrieved from https://www.drugabuse.gov/publications/

Pahl, K., Brook, J. S., \& Lee, J. Y. (2013). Adolescent self-control predicts joint trajectories of marijuana use and depressive mood into young adulthood among urban African Americans and Puerto Ricans. Journal of Behavioral Medicine, 37(4), 675-682.

Piquero, A. R., \& Rosay, A. B. (1998). The reliability and validity of Grasmick et al.'s Self-Control Scale: A comment on Longshore et al. Criminology, 36, 157-174.

Pokhrel, P., Herzog, T. A., Black, D. S., Zaman, A. (2013). Adolescent neurocognitive development, self-regulation, and school-based drug use prevention. Prevention Science, 14(3). DOI: 10.1007/s11121-012-0345-7.

Polcin, D. L., \& Korcha, R. (2017). Social support influences on substance abuse outcomes among sober living house residents with low and moderate psychiatric severity. Journal of Alcohol \& Drug Education, 61(1), 51-70.

Prochaska, J. O., \& DiClemente, C. C. (1983). Stages and processes of self-change of smoking: Toward an integrative model of change. Journal of Consulting and Clinical Psychology, 51(3), 390-395.

Rines, A. R., \& Montag, M. L. (1976). Nursing Concepts and Nursing Care. New York: John Wiley \& Sons.

Roblyer, M. I. Z., Betancourth, S., \& Grzywacz, J. G. (2015). Risk and protective factors for lifetime marijuana use among Colombian emergent adults attending college. ISSBD Bulletin, 2015(1), 5-9.

Schaefer, B. P., Vito, A. G., Marcum, C. D., Higgins, G. E., \& Ricketts, M. L. (2015). Examining adolescent cocaine use with Social Learning and Self-Control Theories. Deviant Behavior, 36(10), 823-833.

Shumway, S. T., Bradshaw, S. D., Harris, K. S., \& Baker, A. K. (2013). Important factors of early addiction recovery. Alcoholism Treatment Quarterly, 31(1), 3-24.

Skjærvø, I., Skurtveit, S., Clausen, T., \& Bukten, A. (2017). Substance use pattern, self-control and social network are associated with crime in a substance-using population. Drug and Alcohol Review, 36(2), 245-252.

Smedema, S. M., Pfaller, J., Moser, E., Tu, W. M., \& Chan, F. (2013). Measurement structure of the trait hope scale in persons with spinal cord injury: A confirmatory factor analysis. Rehabilitation Research, Policy, and Education, 27(3), 206-212.

Snyder, C. (2000). Genesis: Birth and growth of hope. In C. R. Snyder, Handbook of hope: Theory, measures, and applications (pp. 25-57). San Diego: Academic Press.

Snyder, C. R., Ritschel, L. A., Rand, K. L., \& Berg, C. J. (2006). Balancing psychological assessments: Including strengths and hope in client reports. Journal of Clinical Psychology, 62(1), 33-46.

Snyder, C. R., Harris, C., Anderson, J. R., Holleran, S. A., Irving, L. M., Sigmon, S. T., Yoshinobu, L., Gibb, J., Langelle, C., \& Harney, P. (1991). The wills and the ways: Development and validation of an individual-differences measure of hope. Journal of Personality and Social Psychology, 60(4), 570-585.

Stotland, E. (1969). The psychology of hope. San Francisco: Jossey-Bass Publishers. 
Strack, S., Carver, C. S., \& Blaney, P. H. (1987). Predicting successful completion of an aftercare program following treatment for alcoholism: The role of dispositional optimism. Journal of Personality \& Social Psychology, 53(3), 579-584.

Sun, I. Y., \& Longazel, J. G. (2008). College students' alcohol-related problems: A test of competing theories. Journal of Criminal Justice, 36(6), 554-562.

Venables, N. C., Foell, J., Yancey, J. R., Beaver, K. M., lacono, W. G., \& Patrick, C. J. (2018). Integrating criminological and mental health perspectives on low selfcontrol: A multidomain analysis. Journal of Criminal Justice, 56, 2-10.

Vera, E. P., \& Moon, B. (2013). An empirical test of Low Self-Control Theory among Hispanic youth. Youth Violence and Juvenile Justice, 11(1), 79-93.

Vohs, K. D., \& Heatherton, T. F. (2000). Self-regulatory failure: A resource-depletion approach. Psychological Science, 11(3), 249-254.

Vohs, K. D., \& Schmeichel, B. J. (2002). What makes hope hopeful? The relationship between hope and self-regulation. Psychological Inquiry, 13(4), 318-321.

Vohs, K. D., Baumeister, R. F., Schmeichel, B. J., \& Tice, D. T. (2001). Decision fatigue: Making multiple personal decisions depletes the self's resources (Unpublished manuscript). Cleveland: Case Western Reserve University.

Weismann, A. (1973). On dying and denying. New York: Behavioral Publications.

Zavala, E., \& Kurtz, D. L. (2017). Using Gottfredson and Hirschi's A General Theory of Crime to explain problematic alcohol consumption by police officers: A test of self-control as self-regulation. Journal of Drug Issues, 47(3), 505-522.

Zemel, O., Einat, T., \& Ronel, N. (2018). Criminal spin, self-control, and desistance from crime among juvenile delinquents: Determinism versus free will in a qualitative perspective. International Journal of Offender Therapy and Comparative Criminology, 62(15), 47394757. 